\title{
Krill caught by predators and nets: differences between species and techniques
}

\author{
K. Reid*, P. N. Trathan, J. P. Croxall, H. J. Hill \\ British Antarctic Survey, Natural Environment Research Council, High Cross, Madingley Road, \\ Cambridge CB3 0ET, United Kingdom
}

\begin{abstract}
Samples of Antarct2c krill collected from 6 seabird species and Antarctic fur seal dunng February 1986 at South Georgia were compared to krill from scientific nets fished in the area at the same time. The length-frequency distribution of krill was broadly similar between predators and nets although the krill taken by diving species formed a homogeneous group which showed significant differences from krill taken by other predators and by nets. There were significant differences in the maturity/sex stage composition between nets and predators; in particular all predator species showed a consistent sex bias towards female krill. Similarities in the krill taken by macaroni (offshore feeding) and gentoo (inshore feeding) penguins and differences between krill taken by penguins and albatrosses suggest that foraging techniques were more important than foraging location in influencing the type of krill in predator diets. Most krill taken by predators were adult; most female krill were sexually active (particularly when allowance is made for misclassification bias ansing from predator digestion). Because female krill are larger, and probably less manouverable, than males, the biased sex ratio in predator diets at this time of year may reflect some combination of selectivity by predators and superior escape responses of male krill. Overall, adult, sexually active female krill, forming $40 \%$ by number of the local krill population, may comprise 60 to $70 \%$ by number and 75 to $88 \%$ by mass of the krill taken by their main seabird and seal predators at South Georgla at the time of peak local demand in February.
\end{abstract}

KEY WORDS: Antarctic krill - Euphausla superba South Georgia Penguins Fur seals Albatrosses

\section{INTRODUCTION}

Antarctic krill Euphausia superba is the single most important prey species taken by a range of higher predators during the breeding season at South Georgia (Croxall \& Prince 1980, Croxall et al. 1988, in press). In order to assess the importance of this predation on the local krill population and in particular on its population dynamics, it is vital to know which component of the krill population is exploited by different predators. It is also important to assess the extent to which krill in the diet of predators reflects the krill available locally (e.g. as indicated by samples taken by scientific nets), particularly in relation to the use of predators as indicators of changes in the local krill population.

·E-mail:k.reid@bas.ac.uk
Despite the importance of these topics, first investigated by Croxall \& Pilcher (1984) and Croxall et al. (1985b), there have only been 2 subsequent critical studies. Nicol (1993) addressed the problem of comparability of net samples and krill collected from predators. He found that Antarctic petrels Thalassoica antarctica took larger krill than those caught in simultaneous net samples, attributing this to nets and birds sampling different populations of krill, either in terms of spatial distribution or arising from differential selection/avoidance of krill between birds and nets.

Hill et al. (1996 this issue) examined the differences between krill in the diet of macaroni penguins Eudyptes chrysolophus and from scientific nets and found that the krill taken by penguins were significantly larger, with a distinct bias towards adult females. They ascribed these differences to a combination of selection of female krill by penguins associated 
with a more effective escape response of male compared to female krill.

The aim of this study was to extend the work of Hill et al. (1996) by examining the length and maturity/sex stages of krill taken simultaneously by a range of predators breeding at South Georgia at a time when contemporaneous local net-caught krill were available for comparison. Predator species were selected for this study to include those with various degrees of dependence on krill and with different foraging ranges and techniques thereby allowing comparison not only between krill in nets and predators but also between predators with differing foraging ecologies.

\section{METHODS}

Study species. The species chosen (with the percentage by mass of krill in the diet in 1986; see Croxall ct al. in press) were: grey-headed albatross Diomedea chrysostoma $(16 \%)$, black-browed albatross $D$. melanophris $(39 \%)$, white-chinned petrel Procellaria aequinoctialis (59\%) Antarctic prion Pachyptila desolata (52\%), gentoo penguin Pygoscelis papua (69\%), macaroni penguin (95\%) and Antarctic fur seal Arctocephalus gazella (mass composition cannot be calculated but krill is consistently the most important component of the diet, occurring in 71 to $100 \%$ of samples; Reid \& Arnould 1996).

Collection of samples. All net-caught krill were taken using a rectangular midwater trawl (RMT8) around South Georgia between 4 and 24 February 1986 following the method described in Hill et al. (1996). The collection of samples from seabirds was by natural regurgitation or lavaging, as described in Croxall et al. (in press); Antarctic fur seal samples were collected by lavaging adult females returning to suckle pups. All predators were sampled at Bird Island, South Georgia at approximately weekly intervals throughout February 1986.

Krill measurement. The total length (AT) of whole krill from net samples was measured from the front of the eye to the tip of the telson (Lockyer 1973). The total length of krill from predators was estimated using the removed carapace length (RCL) following the methods and using the maturity/sex stage specific equations in Hill (1990). Maturity/sex stages of krill were assessed according to the key in Makarov \& Denys (1981) using the nomenclature of Morris et al. (1988) adapted by Hill (1990) for predator samples. This resulted in 3 maturity stages for female krill: sub-adult (FS), nonsexually mature adult females (females without spermatophores) (FA1) and, because of the problems assessing ovarian content of partially digested krill, a category for sexually active adult female krill (females with spermatophores) (FAS) which covers FA2 to FA4. There were 2 categories for male krill: sub-adult (MS) and a combined category--since the only difference between MA1 and MA2 krill is that the latter has spermatophores in the ejaculatory duct which can be 'easily ejected by exerting pressure' (Makarov \& Denys 1981), a distinct possibility when ingested by a predator, these 2 categories were combined and are referred to simply as adult male (MA). It is not possible to sex juvenile krill (J) and these formed a separate category.

\section{RESULTS}

\section{Krill size (length)}

The length range of krill taken by all predator species was broadly similar to that taken in scientific nets (AT, 44 to $64 \mathrm{~mm}$ ) but, apart from white-chinned petrels and Antarctic prions, the length-frequency distributions were skewed towards the larger size classes of krill (Fig. 1). However only the length-frequency distributions of krill from gentoo penguins, macaroni penguins and Antarctic fur seals, which differed significantly from the other predator species but not from each other, were significantly different from net samples (Table 1). The length of krill taken by the remaining species was not different from net samples nor from each other, except in the case of the grey-headed albatross (Table 1).

\section{Krill sex and maturity stage}

Sexually active adult female krill (FAS) was the most numerous maturity/sex stage in net samples and in the diet of predators (Fig. 2). However, there were significant differences in the maturity/sex stage composition between all predator species and between net samples and predator species (Table 2). The smallest difference existed between grey-headed and black-browed albatrosses while the largest differences existed between net samples and both species of penguins (Table 2) Detailed comparison of the maturity/sex stage composition of krill taken by predators and nets suggests that all predators took more non-sexually mature adult female krill (FA1) than expected (with the exception of the grey-headed albatross) and fewer adult male krill (MA) than expected (Table 3). Grey-headed and black-browed albatrosses took more MA than subadult male krill (MS) (Fig 2), in contrast to all other species which took more MS than MA; furthermore the proportion of MA in samples from both species of albatross and from white-chinned petrel was greater than in either macaroni or gentoo penguins (Fig. 2). 


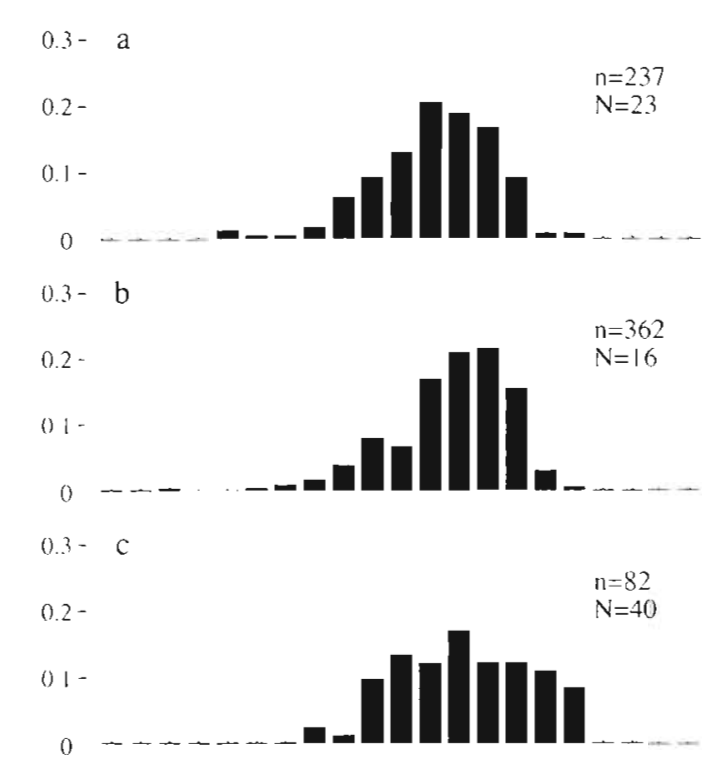

$0.3-\mathrm{d}$
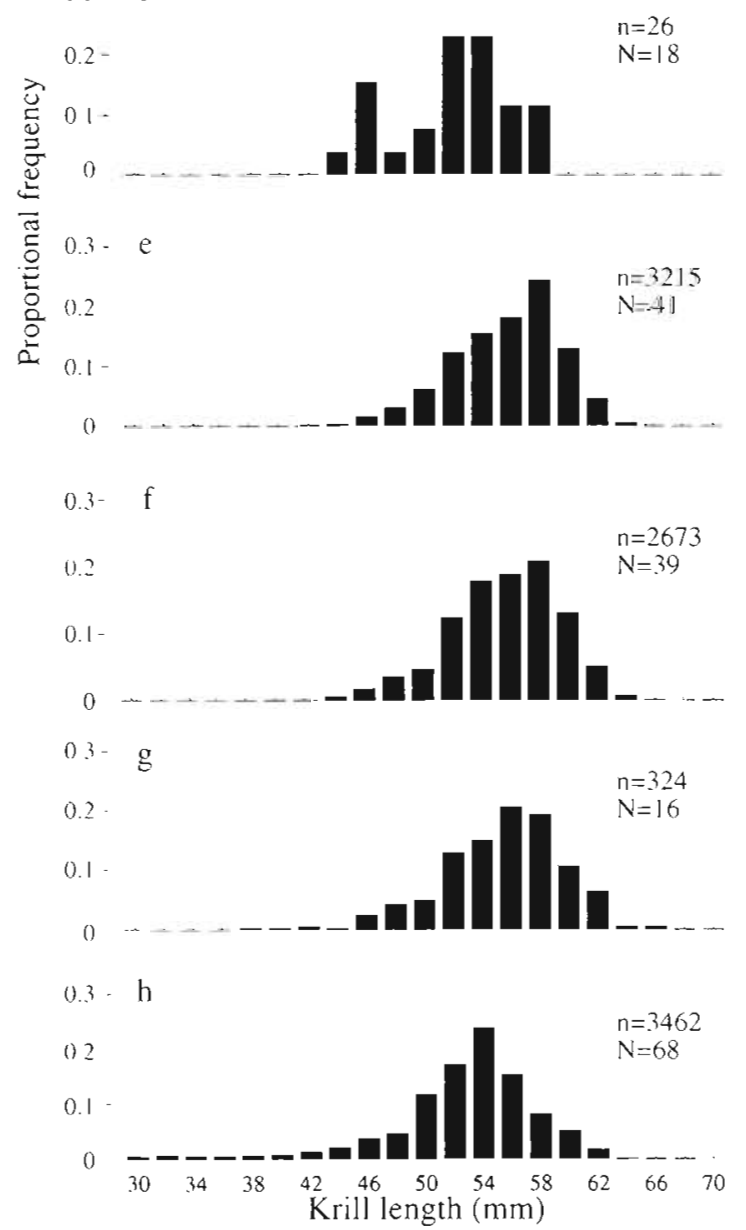

Fig. 1 Length-frequency distribution of krill from predators and nets around South Georgia during February 1986. Sample sizes are for number of krill measured $(n)$ and number of individual predators/nets (N) contributing samples. (a) Greyheaded albatross; (b) black-browed albatross; (c) whitechinned petrel; (d) Antarctic prion; (e) gentoo penguin; (f) macaroni penguin; (g) Antarctic fur seal; (h) net-caught krill
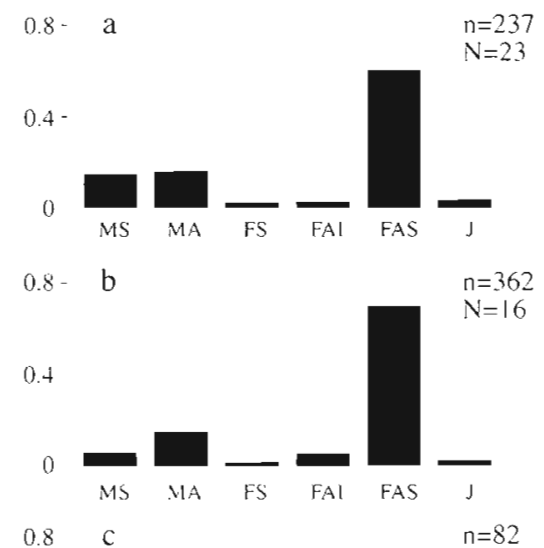

$\begin{array}{ll}0.8 \quad C \quad & n=82 \\ & N=40\end{array}$
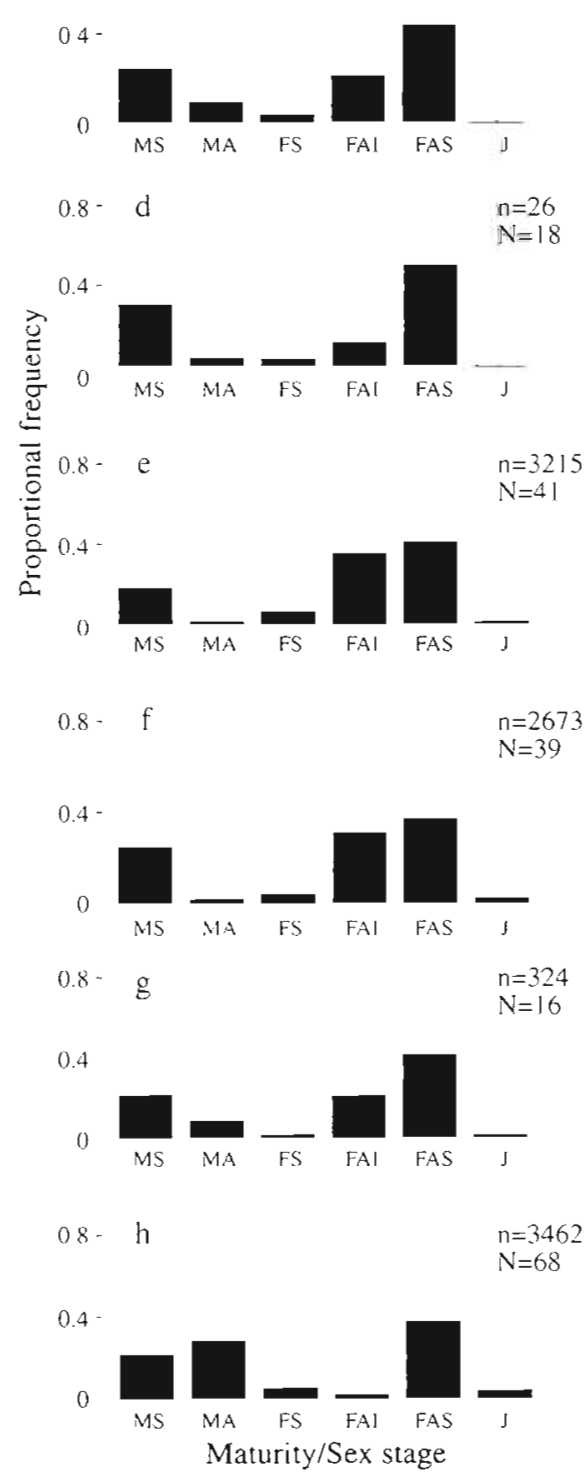

Fig. 2. Maturity/sex stage composition of krill from predators and nets around South Georgia during February 1986. MS: sub-adult male; MA: adult male; FS: sub-adult female; FA1: adult female without spermatophores; FAS: adult female with spermatophores; J: juvenile. Sample size convention and groups $(\mathrm{a}-\mathrm{h})$ as in Fig. 1 
Table 1. Comparison of length-frequency distributions of krill taken by predators and scientific nets (NETS) at South Georgia. Values are maximum difference value $\left(D_{\max }\right)$ from Kolmogorov-Smirnov 2-sample test: Levels of significance are "p<0.05, ${ }^{\prime} p<$ 0.01 and $\cdots p<0.001$ ns is not significant. GHA: grey-headed albatross; BBA: black-browed albatross; WCP: white-chinned petrel; AP: Antarctic prion; GEN: gentoo penguin, MAC: macaroni penguin; AFS: Antarctic fur seal $(n=324)$

\begin{tabular}{|c|c|c|c|c|c|c|c|c|}
\hline & $\mathrm{n}$ & (iil 1 & $\mathrm{BBA}$ & WCP & AP & GEN & $M A C$ & AFS \\
\hline NETS & 3462 & $0.079 \mathrm{~ns}$ & $0.098 \mathrm{~ns}$ & $0.162 \mathrm{~ns}$ & $0.086 \mathrm{~ns}$ & $0.297 \cdots$ & $0.280^{\cdots} \cdots$ & $0.278^{\cdots}$ \\
\hline GHA & 237 & & $0.148 \cdots$ & $0.207^{\bullet}$ & $0.091 \mathrm{~ns}$ & $0.327 \cdots$ & $0.310^{\cdots} \cdots$ & $0.308 \cdots$ \\
\hline $\mathrm{BBA}$ & 362 & & & $0.159 \mathrm{~ns}$ & $0.175 \mathrm{~ns}$ & $0.234^{\cdots}$ & $0.210^{\cdots} \cdots$ & $0.189^{\cdots}$ \\
\hline WCP & 66 & & & & $0.208 \mathrm{~ns}$ & $0.167^{\circ}$ & $0.160^{\circ}$ & $0.208^{\cdots}$ \\
\hline $\mathrm{AP}$ & 26 & & & & & $0.375 \cdots$ & $0.358^{\cdots} \cdot$ & $0.356^{\cdots}$ \\
\hline GEN & 3215 & & & & & & $0.024 \mathrm{~ns}$ & $0.045 \mathrm{~ns}$ \\
\hline MAC & 2673 & & & & & & & $0.030 \mathrm{~ns}$ \\
\hline
\end{tabular}

Table 2. Overall comparison of maturity/sex stage composition of krill taken by predators and scientifıc nets at South Georgia. Values are chi-square ( $5 \mathrm{df}$ ) and all are significant at $\mathrm{p}<0.01 \mathrm{df}$. Antarctic prion is not included in this analysis due to small sample size. For abbreviations see Table 1

\begin{tabular}{|c|c|c|c|c|c|c|c|}
\hline & $\mathrm{n}$ & GHA & BBA & WCP & GEN & $M A C$ & AFS \\
\hline NETS & 3462 & 51.6 & 169.1 & 107.2 & 1933.7 & 1541.2 & 330.0 \\
\hline GHA & 237 & & 16.9 & 36.3 & 356.5 & 261.9 & 62.5 \\
\hline $\mathrm{BBA}$ & 362 & & & 47.7 & 452.8 & 381.8 & 103.1 \\
\hline WCP & 66 & & & & 44.3 & 23.8 & $-^{a}$ \\
\hline GEN & 3215 & & & & & 60.8 & 129.6 \\
\hline MAC & 2673 & & & & & & 77.9 \\
\hline
\end{tabular}

Table 3. Comparison between predators and nets of the contribution made by each maturity/sex stage of krill. Symbols indicate magnitude of difference based on the use of chi-square test. ${ }^{++}{ }^{++}$Observed values greater than expected $\left({ }^{+} p<0.05,{ }^{++} p<0.01\right.$ at $1 \mathrm{df}),{ }^{--}$observed less than expected $\left(-p<0.05,{ }^{--} p<0.01\right.$ at $\left.1 \mathrm{df}\right)$, no significant difference. For abbreviations see Table 1

\begin{tabular}{|c|c|c|c|c|c|c|c|}
\hline $\begin{array}{l}\text { Maturity } \\
\text { sex stage }\end{array}$ & GHA & $\mathrm{BBA}$ & WCP & AP & GEN & MAC & AFS \\
\hline MS & $5.15^{-}$ & $41.10^{--}$ & $0.18^{()}$ & $0.90^{\circ}$ & $19.57^{--}$ & $10.19^{t+}$ & $0.04^{\circ}$ \\
\hline MA & $13.01^{--}$ & $24.22^{--}$ & $8.90^{--}$ & $5.62^{-}$ & $864.91^{--}$ & $682.41^{--}$ & $54.71^{--}$ \\
\hline FS & $4.43^{-}$ & $9.02^{--}$ & $1.78^{\circ}$ & $0.10^{\circ}$ & $21.86^{--}$ & $20.10^{--}$ & $0.48^{\circ}$ \\
\hline FA1 & $0.16^{\circ}$ & $15.87^{++}$ & $110.51^{++}$ & $10.54^{t+}$ & $16203.95^{++}$ & $10267.86^{+t}$ & $529.80^{++}$ \\
\hline FAS & $32.67^{++}$ & $97.77^{++}$ & $0.64^{\circ}$ & $1.00^{\circ}$ & $9.50^{++}$ & $0.36^{\circ}$ & $1.21^{\circ}$ \\
\hline$J$ & $0.24^{\circ}$ & $3.01^{\circ}$ & $2.67^{\prime \prime}$ & $1.05^{\circ}$ & $72.39^{--}$ & $24.15^{--}$ & $6.32^{-}$ \\
\hline
\end{tabular}

\section{DISCUSSION}

Although the contribution of krill to the diet of each predator species varied considerably (from $16 \%$ in grey-headed albatrosses to $95 \%$ in macaroni penguins), the size range of krill taken was remarkably consistent between species. Small krill (AT $<45 \mathrm{~mm}$ ) were generally absent from predator diets, whereas large krill (AT > $56 \mathrm{~mm}$ ) were more abundant than in net hauls. The most abundant maturity/sex stage of krill in net samples, sexually active adult female krill (FAS), was also the most numerous in predator diets. However, non-sexually active adult female krill (FA1) were relatively more numerous in predator diets. In contrast adult male krill (MA) were much more common in net samples, whereas sub-adult male krill (MS) were equally represented in both predator and net samples. Together this produced an overall bias towards female krill in the samples from each predator species, when compared with net samples. The extent to which net caught krill reflect the true sex and size composition of the local krill population is influenced by several biases associated with avoidance of nets particualrly by large krill (Hovekamp 1989). Although nets produce a biased sample, steps can be taken to reduce these biases by controlling the timing and 
depth of deployment (Everson \& Bone 1986). When comparing the differences between net-caught krill and those taken by macaroni penguins, Hill et al. (1996) reviewed the role of biases introduced by the sampling procedure and concluded that these were unlikely to be the predominant cause of the observed differences.

The greater than expected abundance of FA1 krill in the diet of predators, compared to nets, was surprising. One possible explanation is that the morphological criteria used to assess the sexual stages of female krill (the presence of spermatophores as well as the shape and ovarian content of the carapace; Makarov \& Denys 1981) may become less recognisable as a result of ingestion and digestion by predators and thus render adult female krill more liable to classification as FA.1 rather than FAS. Since adult female krill undergo alternate periods of shrinkage and rapid growth, associated with post-spawning sexual regression and rematuration (Thomas \& Ikeda 1987), one would expect FA1 krill to be smaller than FAS krill. This was the case in net samples where the length-frequency distribution of FA1 krill was significantly different from that of FAS krill. However, no such difference existed in krill from gentoo penguins, macaroni penguins or Antarctic fur seals (the 3 species with the largest samples of FA1 and FAS krill; Table 4). Comparison of the lengthfrequency of FA1 krill from these 3 predators with both FA.1 and FAS krill from nets indicates much greater similarity to FAS, rather than FA1, krill from nets (Table 5). This supports the hypothesis that some proportion of FA1 krill, potentially equal to the difference between the proportion of FA1 and FAS krill in nets and predator diets, may in fact be FAS krill whose spermatophores have become detached and/or the carapace shape and size of ovary have been modified as a result of digestion. However, while it seems plausible that damage to krill by predators can lead to

Table 4. Comparison of the length-frequency distribution of FAland FAS krill from scientific nets (NETS) (FA1, $\mathrm{n}=75$; FAS, $n=1302$ ) and gentoo penguin (GEN) (FA1, $n=1132$; FAS, $n=1326$ ), macaronl penguin (MAC) (FA1, $n=829$; FAS, $\mathrm{n}=994$ ) and Antarctic fur seal (AFS) (FA1, $\mathrm{n}=68$, FAS, $\mathrm{n}=$ 135 ). Values (maximum difference $\left(D_{\max }\right)$ from KolmogorovSmirnor 2 -sample test] above the diagonal compare FA1 krill; values (in bold) on the diagonal compare FA1 and FAS krill; values below the diagonal compare FAS krill. '-Significant difference at $p<0.01$; ns is not significant

\begin{tabular}{|lllll|}
\hline & NETS & GEN & MAC & AFS \\
\hline NET & $\mathbf{0 . 3 4 8} \cdots$ & $0.580 \cdots$ & $0.588 \cdot$ & $0.677 \cdots$ \\
GEN & $0.189 \cdots$ & $\mathbf{0 . 0 4 4 n s}$ & $0.041 \mathrm{~ns}$ & $0.142 \mathrm{~ns}$ \\
MAC & $0.270 \cdots$ & $0.081 \mathrm{~ns}$ & $\mathbf{0 . 0 3 1 n s}$ & $0.098 \mathrm{~ns}$ \\
AFS & $0.291 \cdots$ & $\mathbf{0 . 1 0 2 n s}$ & $0.034 \mathrm{~ns}$ & $\mathbf{0 . 0 7 9 n s}$ \\
\hline
\end{tabular}

Table 5. Comparison of the length-frequency distribution of FA1 krill from predators with FA1and FAS krill from scientific nets. Values are maximum difference $\left(D_{\max }\right)$ from Kolmogorov-Smirnov 2-sample test; sample sizes are as in Table 4. Differrences are significant at: $p<0.05, \cdots p<0.10$

\begin{tabular}{|lcc|}
\hline Predator FA1 & Net FA1 & Net FAS \\
\hline Gentoo penguin & $0.580^{\circ}$ & $0.232^{\circ}$ \\
Macaroni penguin & $0.588^{\circ}$ & $0.240^{\circ}$ \\
Antarctic fur seal & $0.677^{\circ}$ & $0.329^{\circ}$ \\
\hline
\end{tabular}

under-estimates of the more advanced maturity stages within a sex, this cannot explain the sex bias in krill which is common to all predator species studied.

Since FAS krill are not only the most numerous but also the largest krill available (Fig. 3), it is possible that the sex bias is simply a consequence of size selectivity on the part of the predators, such that targeting the largest krill available produces a coincidental bias towards female krill. Alternatively, as Hill et al. (1996) suggested for macaroni penguins, the predominance of female krill may result from male krill being more adept at avoiding capture, due to a combination of superior hydrodynamic shape leading to faster swimming speed (Kils 1981) and increased sensory acuity (Makarov \& Denys 1981). MS krill outnumber MA krill in all predator species, except albatrosses, which is the reverse of the situation in net samples (Fig. 2). Even though the length-frequency distributions of MS and MA krill overlap (Fig. 3), the older, more mature male krill have a greater abdominal muscle mass and larger pleopods which probably confer greater mobility (Farber-Lorda 1990); hence MA krill are likely to be more adept at avoiding capture than both sub-adult male and female krill. Since the selection of the largest krill available by predators and the enhanced ability of adult male krill to avoid capture are not mutually exclusive, it is likely that they both act to produce a bias towards female krill in the diet of predators. Since the sex ratio is approximately equal in net samples, this implies that the mechanism by which male krill avoid capture by predators is ineffective in escaping nets. As O'Brien (1987) suggested, krill may have different types and thresholds of escape response to different levels of threat by predators. In particular the escape response of krill to a single, large, relatively slow moving object, such as a net, may differ considerably from the response to a number of small, fast moving objects, readily recognisable as predators, such as seals or penguins.

The striking similarities in the krill taken by gentoo and macaroni penguins, 2 species with apparently mutually exclusive foraging areas (gentoo foraging inshore with macaroni foraging offshore; Hunt et al. 


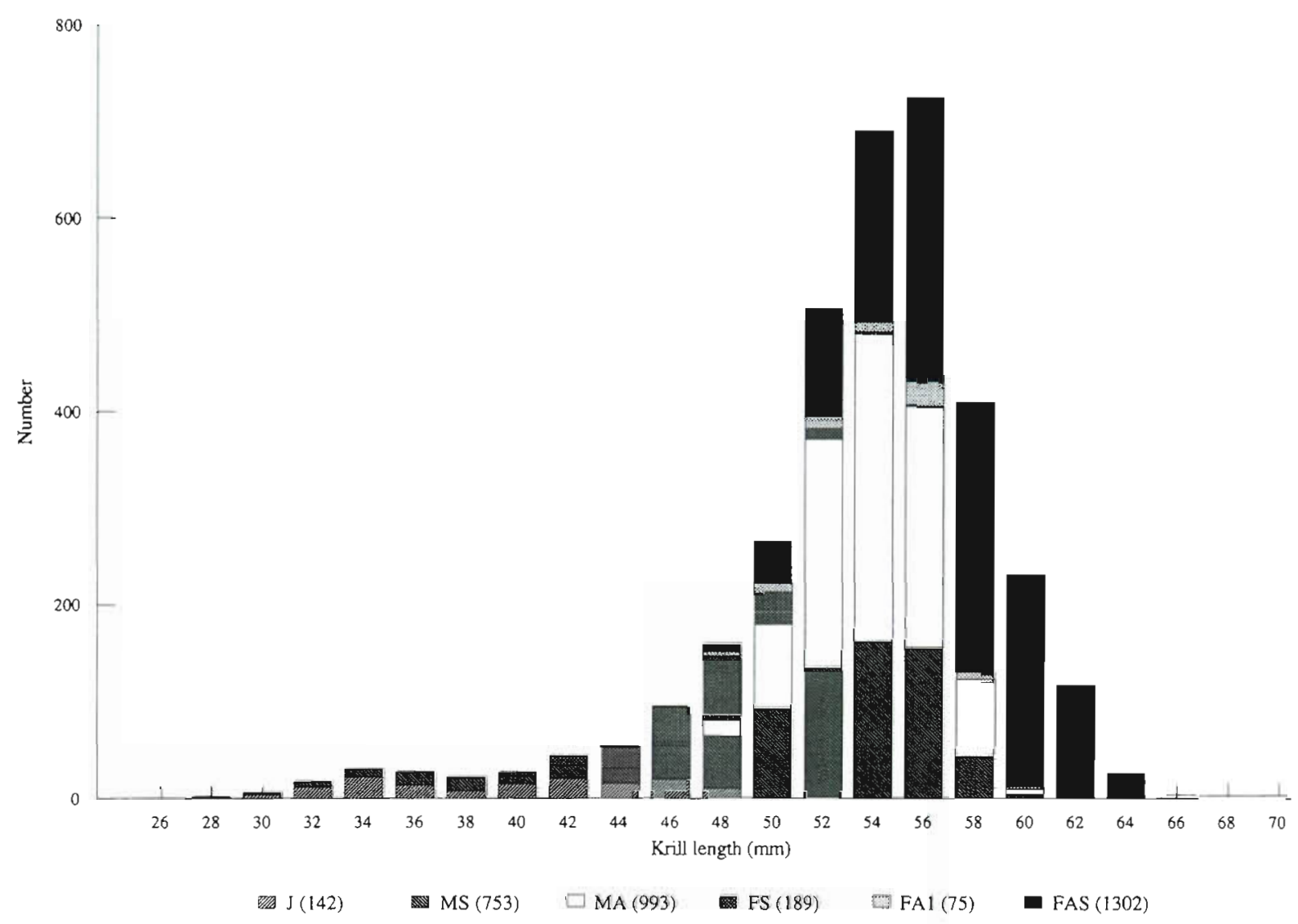

Fig. 3. Length-frequency distribution of each maturity/sex stage of krill from net-caught samples taken around South Georgia during February 1986. Abbreviations as in Fig. 2. Sample sizes are given in parenthesis

1992, Williams et al. 1992) and the difference between these krill and those in the diet of grey-headed and black-browed albatrosses, suggest that foraging techniques are more important than foraging ranges in determining the characteristics of krill in the diet. The length-frequency distribution of krill in the diet of gentoo and macaroni penguins and Antarctic fur seals each differed significantly from the other predators, but not from each other. In addition, their maturity/sex stage compositions were very similar, particularly in the case of the 2 penguin species; thus the krill in the diet of the 3 species which are highly specialised for feeding by diving (Croxall et al. 1985a, 1993, Williams et al. 1992, Boyd et al. 1994) appears to represent a homogeneous group. The length and maturity/sex stage composition of krill taken by both black-browed and grey-headed albatrosses are also very similar to each other but significantly different from the 'diving' group. The length and maturity/sex stage composition of krill taken by white-chinned petrels appear to be intermediate between the albatrosses and the penguins and this may reflect the intermediate diving capabilities of white-chinned petrels (up to $12 \mathrm{~m}$; Huin 1994) compared to albatrosses (between 3 and $5 \mathrm{~m}$;
Prince et al, 1994) and penguins (mean depth ca $30 \mathrm{~m}$ Williams et al. 1992, Croxall et al. 1993). These different diving capabilities may reflect not only the different depth horizons which the predators may exploit but also the different abilities to pursue individual krill, and thereby achieve a greater potential selectivity.

Krill forms the largest part of the diet in the 'diving' species which are best adapted to exploit krill aggregations. Thus krill may have evolved better adaptations to avoid capture by these specialised predators than to species using surface-seizure techniques. Indeed, Kils (1981) noted that while krill reacted by swimming rapidly away from an object approaching from the side there was much less reaction to an object approaching from above. This suggests that the response of krill to predators feeding from different directions may be different. There are also differences in the timing of feeding by predators such that albatrosses, which are diurnal feeders, and white-chinned petrels, which feed both diurnally and nocturnally. may encounter krill of different size and/or status at or near the surface. This is an effect that may well be modified or enhanced by the diel vertical migration of krill. However, within the 'diving' group gentoo pen- 
guins are diurnal, Antarctic fur seals are principally nocturnal and macaroni penguins feed at both times without this being reflected in differences in krill taken. This suggests that any such influence of temporal changes in the nature of krill available to predators is most pronounced at or near to the surface. Surface feeding species, especially black-browed and greyheaded albatrosses, often feed on krill driven to the surface by underwater predators such as fur seals and penguins (Harrison et al. 1991). It is possible that the more rapid and effective escape response of adult male krill might tend to propel them towards the periphery of the swarm, rendering them more vulnerable to capture by surface-feeding predators, and thus leading to the higher proportion of adult male krill in the diet of albatrosses compared to the other predator species. In explaining the differences in the characteristics of krill taken by different predators there are a variety of potential explanations, not mutually exclusive, that encompass differences in technique and timing of foraging by predators as well as differential responses of krill to those predators.

Having examined some of the potential mechanisms involved it is now possible to re-examine the relative 'sizes' (Fig. 3) and abundances (Fig. 2) of the individual maturity/sex stages of krill, using gentoo and macaroni penguins as examples, and seek to explain their composition in the diet (Table 3 ). The smallest size classes, juvenile (J) and sub-adult females (FS), were relatively uncommon in nets and therefore presumably either unavailable to, or uneconomic (too small) for exploitation by, penguins. Of the remaining stages, MS krill appear to be taken in more or less similar numbers by nets and penguins, suggesting no particular systematic selection, whereas MA krill, perhaps as a result of their more rapid escape response, are considerably underrepresented in penguin diets. FA1 krill are taken in greater than expected proportions compared to nets, although not to the extent indicated in Fig. 2 since this group probably includes a large proportion of damaged FAS (see earlier). This then leaves FAS krill, which are the largest and most numerous stage, but are probably taken in even greater than expected numbers by penguins than by nets, after allowing for misclassification. Therefore it is possible that FAS krill, which formed approximately $40 \%$ of the krill population by number (as represented in nets), may have represented between 60 and $70 \%$ of the number-and between 75 and $88 \%$ of the biomass (Morris et al. 1988) - of the krill taken by predators at this time (the month of peak demand by many local krill predators; Croxall et al. 1985b)

In conclusion, since male and female krill form approximately equal proportions of the krill population, as assessed by scientific nets, the consistent sex bias in the diet of predators probably results from a combination of predators targeting the largest individuals available (which happen to be females) and adult male krill being more adept at avoiding capture. A greater understanding of the dynamics of krill swarms during exploitation by predators and by nets, with particular emphasis on the different escape responses of male and female krill, will be essential to resolving the cause of the differences between krill taken by predators and nets. Such studies should also be extended to include the type of nets used by commercial fisheries.

Acknowledgements. We thank our colleagues at Bird Island in 1986, particularly C. D. Duck, A. J. Hall, R. Lidstone-Scott and $\mathrm{M}$. J. O'Connell for assistance with collection of predator diet samples, and the officers, crew and scientists on board the RRS 'John Biscoe' for collection of net samples. We are grateful to P. Ward for help in sorting and measuring krill from predator and net samples and to J. L. Watkins for many helpful comments and discussions on an earlier draft of the manuscript. We also thank 3 anonymous referees for their valuable comments on the manuscript

\section{LITERATURE CITED}

Boyd IL. Arnould JPY, Barton T, Croxall JP (1994) Foraging behaviour of Antarctic fur seals during periods of contrasting prey abundance. J Anim Ecol 63:703-713

Croxall JP, Briggs DR, Kato A, Naito Y, Watanuki Y, Williams TD (1993) Diving pattern and performance in macaroni penguin Eudyptes chrysolophus. J Zool Lond 230:31-47

Croxall JP, Everson I, Kooyman GL, Ricketts C, Davis RW (1985a) Fur seal diving behaviour in relation to vertical distribution of krill. J Anim Ecol 54:1-8

Croxall JP, McCann TS, Prince PA, Rothery P (1988) Reproductive performance of seabirds and seals at South Georgia and Signy Island, South Orkney Islands, 1976-1987: implications for Southern Ocean monitoring studies. In: Sahrhage D (ed) Antarctic Ocean and resources variability. Springer-Verlag, Berlin, p 261-285

Croxall JP, Pilcher MN (1984) Characteristics of krill Euphausia superba eaten by Antarctic fur seals Arctocephalus gazella at South Georgia. Br Antarct Surv Bull 63:117-125

Croxall JP, Prince PA (1980) Food, feeding ecology and ecological segregation of seabirds at South Georgia. Biol J Linnean Soc 14(1):103-131

Croxall JP, Prince PA, Reid K (in press) Dietary segregation of krill-eating South Georgia seabirds J Zool Lond

Croxall JP, Prince PA, Ricketts C (1985b) Relationships between prey life-cycles and the extent, nature and timing of seal and seabird predation in the Scotia Sea. In: Siegfried WR, Condy PR, Laws RM (eds) Antarctic nutrient cycles and food webs. Springer-Verlag, Berlin, p 516-533

Everson I, Bone DG (1986) Effectiveness of the RMT8 system for sampling krill (Euphausia superba) swarms. Polar Biol $6: 83-90$

Farber-Lorda J (1990) Somatic length relationships and ontogenic morphometric differentiation of Euphausia superba and Thysanoessa macrura of the southwest Indian Ocean during summer (February 1981). Deep Sea Res 37(7): $1135-1143$

Harrison NM, Whitehouse MJ, Heinemann D, Prince PA Hunt GL Jr, Veit RR (1991) Observations of multispecies 
seabird flocks around South Georgia. Auk 108:801-810

Hill HJ (1990) A new method for the measurement of Antarctic krill Euphausia superba Dana from predator food samples. Polar Biol 10:317-320

Hill HJ, Trathan PN, Croxall JP, Watkins JL (1996) A comparison of Antarctic krill Euphausia superba caught in nets and taken by macaroni penguins Eudyptes chrysolophus evidence for selection? Mar Ecol Prog Ser 140:1-11

Hovekamp S (1989) Avoidance of nets by Euphausla pacifica in Dabob Bay. J Plankton Res 1.1:907-924

Huin N (1994) Diving depths of white-chinned petrels. Condor 96:1111-1113

Hunt GL Jr, Heinemann D, Everson I (1992) Distributions and predator-prey interactions of macaroni penguins, Antarctic fur seals, and Antarctic krill near Bird Island, South Georgia. Mar Ecol Prog Ser 86:15-30

Kils U (1981) Swimming behaviour, swimming performance and energy balance of Antarctic krill Euphausia superba Biomass Sci Rep Ser 3. SCAR, Cambridge

Lockyer C (1973) Wet wejght, volume and length correlation in the Antarctic krill Euphausia superba. 'Discovery' Rep 36:152-155

Makarov RR, Denys GJ (1981) Stages of sexual maturity of Euphausia superba Dana. SCAR, Cambridge

This article was submitted to the editor
Morris DJ, Watkins JL, Ricketts C, Buchholz F, Priddle J (1988) An assessment of the merits of length and weight measurements of Antarctic krill Euphausia superba. Br Antarct Surv Bull 79:27-50

Nicol S (1993) A comparison of Antarctic petrel Thalassoica antarctica diets with net samples of Antarctic krill Euphausia superba taken from the Prydz Bay region. Polar Biol 13:399-403

O'Brien DP (1987) Description of escape responses of krill (Crustacea: Euphausiacea), with particular reference to swarming behaviour and the size and proximity of the predator. J Crust Biol 7(3):449-457

Prince PA, Huin N, Weimerskirch H (1994) Diving depths of al.batrosses. Antarct Sci 6(3):353-354

Reid K, Arnould JPY (1996) The diet of Antarctic fur seals Arctocephalus gazella during the breeding season at South Georgia. Polar Biol 16:105-114

Thomas PG, Ikeda T (1987) Sexual regression, shrinkage, rematuration and growth of spent female Euphausia superba in the laboratory. Mar Biol 95:357-363

Williams TD, Briggs DR, Croxall JP, Naito Y, Kato A (1992) Diving pattern and performance in relation to foraging ecology in the gentoo penguin Pygoscelis papua. $J$ Zool Lond 227:211-230

Manuscript first received: April 28, 1996

Revised version accepted: May 24, 1996 